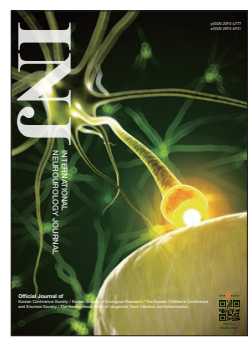

\title{
Irreversible Bladder Remodeling Induced by Fibrosis
}

\author{
Su Jin Kim ${ }^{1}$, Jayoung Kim ${ }^{2,3,4,5}$, Yong Gil Na ${ }^{6}$, Khae Hawn Kim ${ }^{6}$ \\ ${ }^{1}$ Department of Urology, Yonsei University Wonju College of Medicine, Wonju, Korea \\ ${ }^{2}$ Departments of Surgery and Biomedical Sciences, Cedars-Sinai Medical Center, Los Angeles, CA, USA \\ ${ }^{3}$ Samuel Oschin Comprehensive Cancer Institute, Cedars-Sinai Medical Center, Los Angeles, CA, USA \\ ${ }^{4}$ University of California Los Angeles, Los Angeles, CA, USA \\ ${ }^{5}$ Department of Urology, Ga Cheon University College of Medicine, Incheon, Korea \\ ${ }^{6}$ Department of Urology, Chungnam National University Sejong Hospital, Chungnam National University College of Medicine, Sejong, Korea
}

Underactive bladder and impaired bladder compliance are irreversible problems associated with bladder fibrosis. Remodeling of the extracellular matrix is regarded as an important mechanism associated with bladder fibrosis. However, various risk factors and conditions contribute to the functional impairment of the bladder associated with fibrosis, and there is limited knowledge about bladder fibrosis-associated problems in the field of neurourology. Further studies are thus necessary to elucidate the underlying mechanism of bladder fibrosis and to identify effective treatment.

Keywords: Urinary bladder; Fibrosis; Extracellular matrix; Lower urinary tract symptoms; Collagen

- Fund/Grant Support: This research was supported by the Basic Science Research Program through the National Research Foundation of Korea (NRF) funded by the Ministry of Education (2018R1D1A3B07048492).

- Conflict of Interest: SJK and KHK, associate editors of International Neurourology Journal, are the authors of this article. However, they played no role whatsoever in the editorial evaluation of this article or the decision to publish it. Except for that, no potential conflict of interest relevant to this article was reported.

\section{INTRODUCTION}

Bladder trabeculation refers to morphological changes of the bladder detrusor, including smooth muscle hypertrophy and increased collagen deposition in the detrusor extracellular matrix (ECM), resulting in fibrosis of the bladder [1,2]. These morphological changes of the bladder can be observed in patients with various voiding problems, such as neurogenic bladder and bladder outlet obstruction (BOO) [3-6]. Lower urinary tract symptoms (LUTS) in the men with benign prostatic hyperplasia $(\mathrm{BPH})$ are associated with $\mathrm{BOO}$, and the increased intravesical pressure that occurs in men with $\mathrm{BOO}$ induces hypertrophy of the bladder detrusor to overcome $\mathrm{BOO}$. If $\mathrm{BOO}$ is not relieved, irreversible morphological changes of the bladder, such as increased collagen accumulation and fibrosis of the bladder, occur. Fibrosis of the bladder causes the loss of normal detrusor contractility; and therefore, affected patients cannot urinate by themselves [6]. In addition to $\mathrm{BOO}$ associated with $\mathrm{BPH}$, many other conditions are associated with fibrotic changes of the bladder, such as dementia, stroke, cerebral hemorrhage, spinal cord injury, diabetes mellitus, and aging [7].

Common LUTS associated with bladder fibrosis are a weak urinary stream, intermittency, increased residual urine sensation, and abdominal straining during urination because the fibrotic bladder loses normal contractility for expelling urine from the bladder. Medical therapies using parasympathomi-

Corresponding author: Khae Hawn Kim (iD https://orcid.org/0000-0002-7045-8004 Department of Urology, Chungnam National University Sejong Hospital, Chungnam National University College of Medicine, 20 Bodeum 7-ro, Sejong 30099, Korea

Email:kimcho99@cnuh.co.kr

Submitted: April 2, 2021 / Accepted after revision: May 10, 2021 
metics and alpha blockers have been attempted to help urination; however, inconsistent results have been reported regarding the effects of these treatments, and there is no clear evidence that they improve bladder contractility [8-11]. Some patients showed improvement of LUTS and the ability to urinate by themselves, but most patients continue to need indwelling urethral and suprapubic catheters to expel urine from their bladder due to an irreversible loss of bladder contractility [12-15].

At present, no effective treatment methods are available to prevent bladder fibrosis and to recover the impaired bladder contractility associated with bladder fibrosis. Thus, this review deals with the pathophysiology of bladder fibrosis and upcoming treatment based on a literature review.

\section{LUTS AND DECREASED CONTRACTILITY AND COMPLIANCE OF THE BLADDER DETRUSOR ASSOCIATED WITH BLADDER FIBROSIS}

Underactive bladder (UAB) is a LUTS complex characterized by incomplete bladder emptying with a decreased urinary flow rate and increased postvoid residual urine volume [15]. UAB is associated with detrusor underactivity (DU) or acontractile detrusor observed in a urodynamic study. Morphological changes such as bladder fibrosis induced by increased collagen deposition in the detrusor ECM can induce DU and impairment of bladder contractility. According to a study reporting urodynamic results in UAB patients, detrusor hyperreflexia with impaired detrusor contractility (DHIC) was observed, as well as DU or acontractile detrusor [16]. Patients with DHIC experienced storage symptoms such as incontinence or urgency with accompanying symptoms induced by incomplete emptying [17]. These findings suggest that contractile changes associated with bladder fibrosis constitute a complicated process that results in impaired bladder contractility with or without detrusor overactivity. Furthermore, the process of a coexistent voiding problem that is not associated with bladder fibrosis (e.g., stress urinary incontinence) can be a factor that induces incontinence [18-20]. Moreover, Uren et al. [21] reported that patients diagnosed with DU using a urodynamic study showed nocturia, frequent daytime urination, urgency, and incontinence, as well as a weak urinary stream, hesitancy, and abdominal straining during urination. However, Uren et al. [21] did not investigate the etiology of DU, making it impossible to know whether the patients with storage LUTS had other voiding problems unrelated to DU.
Decreased bladder compliance is a change associated with bladder fibrosis. Bladder compliance can be conceptualized as the relationship between a change in bladder volume and a change in detrusor pressure. In general, bladder compliance is expressed as an increase in bladder volume per increment of intravesical pressure [22]. Thus, bladder compliance reflects the flexibility of the bladder. Fibrotic changes of the bladder reduce its flexibility and induce stiffness of the bladder and low bladder compliance. As a result, the intravesical pressure of a stiff bladder with low compliance is increased, and prolonged high intravesical pressure adversely affects renal function [23-26]. Therefore, it is important to improve bladder compliance and reduce the intravesical pressure of the bladder to prevent impairment of renal function. Patients with impaired bladder compliance show urge urinary incontinence [27].

Both UAB and impaired bladder compliance are associated with bladder fibrosis. However, it is unclear about why the consequences of bladder fibrosis sometimes appear as UAB or impaired bladder compliance. Previous studies have suggested that there may be a difference in the subtype of collagen deposition between $\mathrm{UAB}$ and impaired bladder compliance, and that increased proteoglycan deposition in the ECM may also be related factor (Fig. 1) [28-31].

\section{UNDERLYING MECHANISM ASSOCIATED WITH BLADDER FIBROSIS}

Remodeling of the ECM and increased levels of transforming growth factor- $\beta 1$ (TGF- $\beta 1$ ) are regarded as the mechanism underlying bladder fibrosis [32]. The ECM of the bladder consists of collagen, elastin, fibronectins, and proteoglycans. Collagen is the major fibrous protein of the ECM and plays a role in providing tensile strength to the bladder. Collagen types I and III are the most important subtypes of collagen in the ECM [3335]. Unlike collagen, elastin induces recoil of the ECM after stretching during urination. Conditions such as $\mathrm{BOO}$ and neurogenic bladder associated with mechanical or chemical stresses induce fibroblastic and inflammatory responses in the ECM. These responses dysregulate fibroblast secretion of matrix metalloproteinases (MMPs) and tissue inhibitors of MMPs (TIMPs) and increase ECM deposition. Prolonged ECM deposition increases the production of TIMPs which are associated with fibrosis and fibrotic changes of the bladder occur [36-38]. Moreover, increased levels of TGF- $\beta 1$ induce fibrosis by stimulating collagen production through binding to serine/threonine ki- 


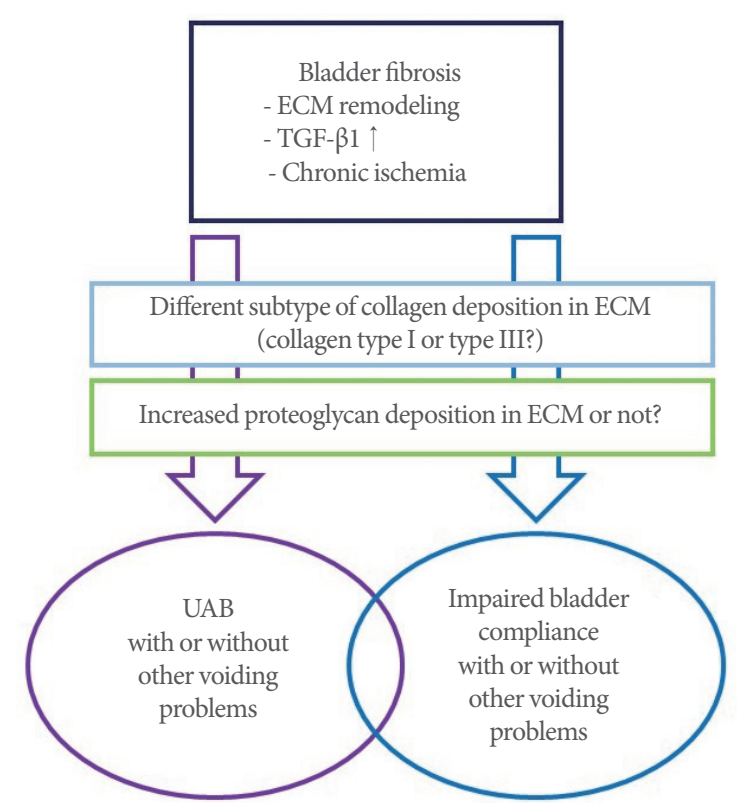

Fig. 1. Potential theoretical mechanism of bladder fibrosis-associated voiding problems. ECM, extracelluar matrix; TGF- $\beta 1$, transforming growth factor- $\beta 1 ; \mathrm{UAB}$, underactive bladder.

nase receptors on the cell surface, cause the phosphorylation of intracellular Smad2/3 transcription factors [39,40].

Chronic bladder ischemia may be a factor associated with bladder fibrosis. Previous studies have suggested that cardiovascular and metabolic diseases related to endothelial dysfunction decrease blood flow to the bladder. In turn, chronic ischemia of the bladder was found to increase oxidative stress and inflammatory cytokine levels, which might be associated with bladder fibrosis induced by nerve damage [41].

\section{UPCOMING THERAPEUTIC METHODS TO PREVENT AND TREAT BLADDER FIBROSIS}

There is currently no effective treatment for LUTS associated with bladder fibrosis. Conventional medical treatment fails in most patients with voiding problems induced by bladder fibrosis, and these patients require catheterization to expel urine from the bladder. Therefore, studies have aimed to prevent and restore bladder fibrosis using antifibrotic agent such as relaxin. Ikeda et al. [42] showed that human relaxin-2 reversed fibrosis, decreased collagen deposition, and increased bladder compliance and detrusor contractility in patients with radiation-induced bladder fibrosis. A recent study reported that relaxin receptors were present in the dome and trigone of the human bladder and that in vitro relaxin stimulation upregulated MMP2 and decreased TGF- $\beta 1$ [43].

Efforts have been made to apply stem cell and gene therapy to improve UAB associated with bladder fibrosis [20]. Several preclinical studies used various types of stem cells and showed improvements in detrusor contractility. A pilot study by Levanovich et al. [44] showed enhanced urination and a reduced need for clean intermittent catheterization in a patient with $\mathrm{UAB}$ after an intradetrusor injection of autologous muscle-derived stem cells.

\section{CONCLUSIONS}

Bladder fibrosis is an irreversible change of the bladder that is associated with $\mathrm{UAB}$ and impaired bladder compliance. Although bladder fibrosis is a serious problem, it has been difficult to elucidate its exact underlying mechanism and risk factors. Moreover, the progression of voiding problems associated with bladder fibrosis cannot be predicted due to the unknown characteristics of conditions associated with bladder fibrosis. There problematic characteristics are also obstacles to the prevention and treatment of bladder fibrosis. Therefore, further studies are essential to elucidate the underlying mechanism of bladder fibrosis and to identify effective treatments.

\section{AUTHOR CONTRIBUTION STATEMENT}

- Conceptualization: SJK

- Data curation: $J K$

- Formal analysis: YGN

- Funding acquisition: KHK

- Methodology: JK

- Project administration: KHK

- Visualization: YGN

-Writing-original draft: SJK

-Writing-review \& editing: SJK

\section{ORCID}

Su Jin Kim https://orcid.org/0000-0002-1917-2780 Jayoung Kim https://orcid.org/0000-0002-3683-4627 Yong Gil Na https://orcid.org/0000-0002-0794-5459 Khae Hawn Kim 


\section{REFERENCES}

1. Barnard RJ, Dixon JS, Gosling JA. A clinical and morphological evaluation of the trabeculated urinary bladder. Prog Clin Biol Res 1981;78:285-8.

2. Jung JH, Cho SY, Yoo C, Oh SJ. Establishment of the novel cystoscopic classification for bladder trabeculation of neurogenic bladder. Urology 2014;84:515-9.

3. Selby B, Hidas G, Chuang KW, Soltani T, Billimek J, Kaplan S, et al. Development and validation of a bladder trabeculation grading system in pediatric neurogenic bladder. J Pediatr Urol 2020;16:36770.

4. Hoffberg HJ, Cardenas DD. Bladder trabeculation in spinal cord injury. Arch Phys Med Rehabil 1986;67:750-3.

5. Bai SW, Park SH, Chung DJ, Park JH, Shin JS, Kim SK, et al. The significance of bladder trabeculation in the female lower urinary system: an objective evaluation by urodynamic studies. Yonsei Med J 2005;46:673-8.

6. Fusco F, Creta M, De Nunzio C, Iacovelli V, Mangiapia F, Li Marzi V, et al. Progressive bladder remodeling due to bladder outlet obstruction: a systematic review of morphological and molecular evidences in humans. BMC Urol 2018;18:15.

7. Santos-Pereira M, Charrua A. Understanding underactive bladder: a review of the contemporary literature. Porto Biomed J 2020;5: e070.

8. Gaitonde S, Malik RD, Christie AL, Zimmern PE. Bethanechol: is it still being prescribed for bladder dysfunction in women? Int J Clin Pract 2019;73:e13248.

9. Osman NI, Chapple CR. Are there pharmacotherapeutic options for underactive bladder? Eur Urol Focus 2018;4:6-7.

10. Yamanishi T, Yasuda K, Kamai T, Tsuji T, Sakakibara R, Uchiyama T, et al. Combination of a cholinergic drug and an $\alpha$-blocker is more effective than monotherapy for the treatment of voiding difficulty in patients with underactive detrusor. Int J Urol 2004;11:88-96.

11. Chang SJ, Chiang IN, Yu HJ. The effectiveness of tamsulosin in treating women with voiding difficulty. Int J Urol 2008;15:981-5.

12. Bayrak Ö, Dmochowski RR. Underactive bladder: a review of the current treatment concepts. Turk J Urol 2019;45:401-9.

13. Aggarwal H, Zimmern PE. Underactive bladder. Curr Urol Rep 2016;17:17.

14. Dewulf K, Abraham N, Lamb LE, Griebling TL, Yoshimura N, Tyagi $\mathrm{P}$, et al. Addressing challenges in underactive bladder: recommendations and insights from the Congress on Underactive Bladder (CURE-UAB). Int Urol Nephrol 2017;49:777-85.

15. Chapple CR, Osman NI, Birder L, Dmochowski R, Drake MI, van
Koeveringe G, et al. Terminology report from the International Continence Society (ICS) Working Group on Underactive Bladder (UAB). Neurourol Urodyn 2018;37:2928-31.

16. Li X, Liao LM, Chen GQ, Wang ZX, Lu TJ, Deng H. Clinical and urodynamic characteristics of underactive bladder: data analysis of 1726 cases from a single center. Medicine (Baltimore) 2018;97: e9610.

17. Uren AD, Drake MJ. Definition and symptoms of underactive bladder. Investig Clin Urol 2017;58(Suppl 2):S61-7.

18. Natale F, Illiano E, Zucchi A, Balzarro M, La Penna C, Costantini E. Transobturator mid-urethral sling in females with stress urinary incontinence and detrusor underactivity: effect on voiding phase. Int Urogynecol J 2019;30:1519-25.

19. Ko KJ, Suh YS, Sung HH, Ryu GH, Lee M, Lee KS. Assessing the readjustable sling procedure (Remeex system) for female stress urinary incontinence with detrusor underactivity. Int Neurourol J 2017;21:116-20.

20. Cho KJ, Kim JC. Management of urinary incontinence with underactive bladder: a review. Int Neurourol J 2020;24:111-7.

21. Uren AD, Cotterill N, Harding C, Hillary C, Chapple C, Klaver M, et al. Qualitative exploration of the patient experience of underactive bladder. Eur Urol 2017;72:402-7.

22. Abrams P, Cardozo L, Fall M, Griffiths D, Rosier P, Ulmsten U, et al. The standardisation of terminology of lower urinary tract function: report from the Standardisation Sub-committee of the International Continence Society. Neurourol Urodyn 2002;21:167-78.

23. Nseyo U, Santiago-Lastra Y. Long-term complications of the neurogenic bladder. Urol Clin North Am 2017;44:355-66.

24. Holmdahl G, Sillen U, Hellström AL, Sixt R, Sölsnes E. Does treatment with clean intermittent catheterization in boys with posterior urethral valves affect bladder and renal function? J Urol 2003; 170:1681-5.

25. Ghoniem GM, Bloom DA, McGuire EJ, Stewart KL. Bladder compliance in meningomyelocele children. J Urol 1989;141:1404-6.

26. Prakash NS, Lopategui DM, Gomez C. Changes in management of poorly compliant bladder in botulinum toxin A era. Curr Urol Rep 2017;18:64.

27. Truss MC, Stief CG, Uckert S, Becker AJ, Schultheiss D, Machtens S, et al. Initial clinical experience with the selective phosphodiesterase-I isoenzyme inhibitor vinpocetine in the treatment of urge incontinence and low compliance bladder. World J Urol 2000;18:43943.

28. Lee BR, Perlman EJ, Partin AW, Jeffs RD, Gearhart JP. Evaluation of smooth muscle and collagen subtypes in normal newborns and those with bladder exstrophy. J Urol 1996;156:2034-6. 
29. Imamura M, Kanematsu A, Yamamoto S, Kimura Y, Kanatani I, Ito $\mathrm{N}$, et al. Basic fibroblast growth factor modulates proliferation and collagen expression in urinary bladder smooth muscle cells. Am J Physiol Renal Physiol 2007;293:F1007-17.

30. Asgari M, Latifi N, Heris HK, Vali H, Mongeau L. In vitro fibrillogenesis of tropocollagen type III in collagen type I affects its relative fibrillar topology and mechanics. Sci Rep 2017;7:1392.

31. Iozzo RY, Schaefer L. Proteoglycan form and function: a comprehensive nomenclature of proteoglycans. Matrix Biol 2015;42:11-55.

32. Koeck I, Burkhard FC, Monastyrskaya K. Activation of common signaling pathways during remodeling of the heart and the bladder. Biochem Pharmacol 2016;102:7-19.

33. Rozario T, DeSimone DW. The extracellular matrix in development and morphogenesis: a dynamic view. Dev Biol 2010;341:126-40.

34. Schaefer L, Schaefer RM. Proteoglycans: from structural compounds to signaling molecules. Cell Tissue Res 2010;339:237-46.

35. Almalki SG, Agrawal DK. Effects of matrix metalloproteinases on the fate of mesenchymal stem cells. Stem Cell Res Ther 2016;7:129.

36. Craig VJ, Zhang L, Hagood JS, Owen CA. Matrix metalloproteinases as therapeutic targets for idiopathic pulmonary fibrosis. Am J Respir Cell Mol Biol 2015;53:585-600.

37. Arpino V, Brock M, Gill SE. The role of TIMPs in regulation of extracellular matrix proteolysis. Matrix Biol 2015;44-46:247-54.

38. da Costa AWF, do Carmo Neto JR, Braga YLL, Silva BA, Lamounier AB, Silva BO, et al. Cardiac Chagas disease: MMPs, TIMPs, Ga- lectins, and TGF- $\beta$ as tissue remodelling players. Dis Markers 2019;2019:3632906.

39. He R, Zhang J, Luo D, Yu Y, Chen T, Yang Y, et al. Upregulation of transient receptor potential canonical type 3 channel via AT1R/ TGF- $\beta 1 / \operatorname{Smad} 2 / 3$ induces atrial fibrosis in aging and spontaneously hypertensive rats. Oxid Med Cell Longev 2019;2019:4025496.

40. Song S, Zhang R, Cao W, Fang G, Yu Y, Wan Y, et al. Foxm1 is a critical driver of TGF- $\beta$-induced EndMT in endothelial cells through Smad2/3 and binds to the Snail promoter. J Cell Physiol 2019;234:9052-9064.

41. Yoshida M, Yamaguchi O. Detrusor underactivity: the current concept of the pathophysiology. Low Urin Tract Symptoms 2014;6:1317.

42. Ikeda Y, Zabbarova IV, Birder LA, Wipf P, Getchell SE, Tyagi P, et al. Relaxin-2 therapy reverses radiation-induced fibrosis and restores bladder function in mice. Neurourol Urodyn 2018;37:244151.

43. Diaz EC, Briggs M, Wen Y, Zhuang G, Wallace SL, Dobberfuhl $\mathrm{AD}$, et al. Characterizing relaxin receptor expression and exploring relaxin's effect on tissue remodeling/fibrosis in the human bladder. BMC Urol 2020;20:44.

44. Levanovich PE, Diokno A, Hasenau DL, Lajiness M, Pruchnic R, Chancellor MB. Intradetrusor injection of adult muscle-derived cells for the treatment of underactive bladder: pilot study. Int Urol Nephrol 2015;47:465-7. 